\section{Time is tissue in optic neuritis}

Neurol Neuroimmunol Neuroinflamm July 2019 vol. 6 no. 4 e578. doi:10.1212/NXI.0000000000000578

Once again, this issue of Neurology ${ }^{\oplus}$ Neuroimmunology \& Neuroinflammation (N2) highlights the diversity of the field with studies on a range of clinical disorders and a variety of research approaches. Optic neuritis in patients with neuromyelitis optica spectrum disorders associated with aquaporin 4 antibodies (AQP4) or myelin oligodendrocyte glycoprotein (MOG) antibodies is considered steroid responsive, although patients can accumulate disability with recurrent attacks. For these patients, Stiebel-Kalish et al. ${ }^{1}$ investigated whether the time from symptom onset to steroid treatment affected outcome. This was a retrospective study of a consecutive cohort of patients after their first AQP4 or MOG antibody-related attack of optic neuritis. The results showed that patients from both cohorts who received treatment within 4 days of symptom onset had improved outcomes compared with patients treated later and that even a 7-day delay negatively affected outcome. The authors suggest that antibody-mediated optic neuritis should potentially be viewed with the same sense of urgency as heart attack or stroke and reminds the reader that for these patients "time is tissue."

Evidence of an antecedent infection with Campylobacter jejuni, cytomegalovirus, or Mycoplasma pneumoniae is frequently observed in patients developing Guillain-Barré syndrome (GBS), Fisher syndrome, or Bickerstaff brainstem encephalitis (BBE). In these patients, the neurologic disorders share a similar pathogenic mechanism that includes elevated antiglycolipid antibodies. These syndromes rarely occur after infection with influenza virus, although influenza is very common across all age groups. In their study, Yamana et al. ${ }^{2}$ collected clinical information and acute-phase serum samples from consecutive patients with GBS, Fisher syndrome, or BBE occurring after influenza infection and compared their findings with a cohort of patients with these syndromes after $C$. jejuni infection. They found that the postinfluenza cohort had a significantly higher rate of Fisher syndrome and that postinfluenza GBS patients had a higher incidence of cranial nerve involvement, sensory disturbances, and ataxia. Antiglycolipid antibodies were detected more frequently in the postcampylobacter group, most commonly antiGM1, whereas in the postinfluenza patients, anti-GQ1b and anti-GT1a were most frequent. The authors point out that GQ1b is densely localized in the paranodal regions of cranial nerves III, IV, and VI, suggesting a mechanistic relationship with the increased occurrence of Fisher syndrome in the postinfluenza patients. Last, nerve conduction studies revealed acute inflammatory demyelinating polyneuropathy in $60 \%$ of the postinfluenza group but only $25 \%$ of the postcampylobacter GBS group. It will be interesting to see how future studies elucidate the reasons why different infectious result in these varying clinical and serologic findings.

Moving from antibody-mediated demyelinating diseases to postinfectious disorders, the study of Brunetti et al. ${ }^{3}$ brings us IgLON5 disease, an interesting and relatively newly described antibodymediated autoimmune-neurodegenerative encephalopathy. IgLON5 disease is characterized by a sleep disorder, gait disturbance, bulbar symptoms, dysautonomia, and sometimes cognitive decline. Both chronic and subacute clinical courses have been described as well as sudden death likely due to dysautonomia and respiratory distress. In most reports, patients did not improve with immunotherapy, which may have been due to long delays between disease onset and

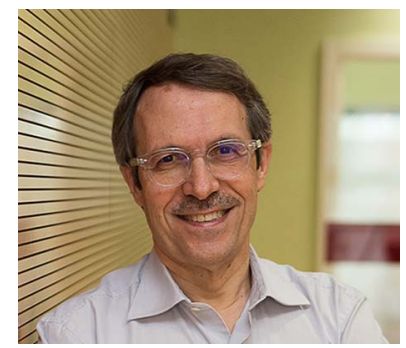

MORE ONLINE

() Editor Summary

NPub.org/N2/edsum 
diagnosis or treatment. Iorio et al. in a well-documented case report describe a patient with a typical IgLON5 syndrome whose disease onset appears to have been 3-5 years before diagnosis. After 1 year of combination immunotherapy (intravenous immunoglobulin prednisone, and azathioprine), the patient showed improvement in the sleep disorder and cognitive impairment. Although additional patients need to be studied, this case suggests that delay in treatment initiation cannot fully explain the lack of response in some of these patients and gives hope to patients with long-standing disease.

Seeing the words "ketogenic diet" in the title of one of the studies in this issue of $\mathrm{N} 2$ supports the diversity of topics noted earlier. As is well known, the ketogenic diet was introduced as a treatment for epilepsy in the 1920s, and its popularity has risen and fallen over the years. In addition to the well-described effects of the ketogenic diet in shifting metabolism from using glycolytic energy toward producing energy primarily from fatty acids, studies in the past few years have shown that the diet attenuates inflammatory biomarkers in the blood and CSF, and these changes associated with benefit in models of experimental autoimmune encephalomyelitis. In light of these results, Brenton et al. ${ }^{4}$ conducted a pilot study of the safety and tolerability of the ketogenic diet in 20 patients with relapsing remitting multiple sclerosis in a 6-month, single-arm, uncontrolled, open-label study. No subject experienced worsening disease on the diet, and almost all adhered to the diet for the entire 6 months, which exceeds adherence rates reported in patients with seizures. The patients showed reductions in body mass index, total fat mass, and depression, along with improvement in the expanded disability status scale scores. At 3 months, there was a significant decrease in serum levels of the proinflammatory adipokine leptin. The results of this intriguing pilot study should lead to prospective studies to define the effect of the diet on disease course.

In addition to these studies, the July issue of $\mathrm{N} 2$ contains 2 reviews on "Treatment strategies of childhood primary angiitis of the central nervous system" and "Immunoglobulin G4related hypertrophic pachymeningitis" and other interesting articles that I hope will catch your attention.

\section{Study funding}

No targeted funding reported.

\section{Disclosure}

Disclosure available: Neurology.org/NN.

\section{References}

1. Stiebel-Kalish H, Hellman MA, Mimouni M, et al. Does time equal vision in the acute treatment of a cohort of AQP4 and MOG optic neuritis? Neurol Neuroimmunol Neuroinflamm 2019;6:e572. doi: 10.1212/NXI.0000000000000572.

2. Yamana M, Kuwahara M, Yoshikawa K, Takeda K, Kusunoki S. Guillain-Barré syndrome and related diseases after influenza virus infection. Neurol Neuroimmunol Neuroinflamm 2019;6:e575. doi: 10.1212/NXI.0000000000000575.

3. Brunetti V, Della Marca G, Spagni G, Iorio R. Immunotherapy improves sleep and cognitive impairment in anti-IgLON5 encephalopathy. Neurol Neuroimmunol Neuroinflamm 2019;6:e577. doi: 10.1212/NXI.0000000000000577.

4. Brenton NJ, Banwell BL, Bergqvist, et al. Pilot study of a ketogenic diet in relapsingremitting multiple sclerosis. Neurol Neuroimmunol Neuroinflamm 2019;6:e565. doi: 10.1212/NXI.0000000000000565. 


\section{Neurology \\ Neuroimmunology \& Neuroinflammation}

Time is tissue in optic neuritis

Josep Dalmau

Neurol Neuroimmunol Neuroinflamm 2019;6;

DOI 10.1212/NXI.0000000000000578

This information is current as of July 5, 2019

\section{Updated Information \& Services}

References

Permissions \& Licensing

\section{Reprints}

including high resolution figures, can be found at:

http://nn.neurology.org/content/6/4/e578.full.html

This article cites 4 articles, 3 of which you can access for free at: http://nn.neurology.org/content/6/4/e578.full.html\#\#ref-list-1

Information about reproducing this article in parts (figures,tables) or in its entirety can be found online at:

http://nn.neurology.org/misc/about.xhtml\#permissions

Information about ordering reprints can be found online: http://nn.neurology.org/misc/addir.xhtml\#reprintsus

Neurol Neuroimmunol Neuroinflamm is an official journal of the American Academy of Neurology.

Published since April 2014, it is an open-access, online-only, continuous publication journal. Copyright

Copyright (C) 2019 The Author(s). Published by Wolters Kluwer Health, Inc. on behalf of the American Academy of Neurology.. All rights reserved. Online ISSN: 2332-7812.

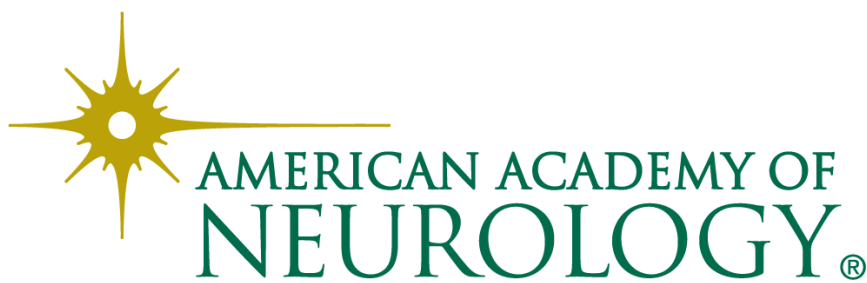

